\title{
O jornalismo estampa a miséria: encarceramento identitário e 'espetacularização' da pobreza
}

\author{
Luiza Gould ${ }^{1}$ \\ Carla Baiense Felix ${ }^{2}$
}

\begin{abstract}
Resumo: Este artigo propõe uma reflexão sobre a "espetacularização" da pobreza na mídia e suas implicações éticas e sociais. Amparado pelos conceitos de espetáculo (DEBORD, 1997 [1967]) e pseudoconcreticidade (KOSIK, 1976), analisa a exposição de sujeitos miseráveis em três reportagens publicadas nos anos 1960 pela revista norte-americana Life e pela brasileira O Cruzeiro. Buscamos entender os regimes de visibilidade sob os quais aparecem e apontar as possíveis consequências do "feixe de luz" (FOUCAULT, 2006 [1977]) sobre corpos marcados pela pobreza. Para tanto, o trabalho discute o "universo carcerário" (BENJAMIN, 1987 [1985]) em que esses personagens são encerrados nas narrativas e o papel da midiatização (SODRÉ, 2002) na sua constituição social.
\end{abstract}

\section{Palavras-chave}

Espetáculo; midiatização; visibilidade; pobreza.

\begin{abstract}
This article proposes a reflection about "spectacularization" of poverty in the media and its ethical and social implications. Supported by the concepts of the spectacle (DEBORD, 1997 [1967]) and pseudoconcreticity (KOSIK, 1976), it analyzes an exposition of individuals in extreme poverty in three special reports published in the 1960s by the magazines Life and O Cruzeiro. We seek to understand the visibility regime under which they appear and we point out the possible consequences of the "beam of light" (FOUCAULT, 2006 [1977]) on bodies marked by poverty. To this end, the paper discusses the "prisonworld" (BENJAMIN, 1987 [1985]) in which these characters are enclosed and the role of mediatization (SODRÉ, 2002) in their social constitution.
\end{abstract}

\section{Keywords}

Spectacle; mediatization; visibility; poverty.

\section{Introdução}

Toda a imagem, assim como todo o dizer, carrega consigo determinados sentidos, enquanto outros possíveis tornam-se invisíveis. Nesse processo de visibilização e invisibilização, com toda a mobilidade que ele pressupõe, mais relevante do que observar o que ora está aparente e o que ora não está é entender como e porque se dá determinado

\footnotetext{
${ }^{1}$ Mestranda em Mídia e Cotidiano na Universidade Federal Fluminense. Pesquisadora vinculada ao grupo Mídias, redes e jovens: usos e apropriações em contextos digitais, e ao Laboratório de Pesquisas Aplicadas (LaPA), ambos do PPGMC/UFF.

${ }^{2}$ Professora Adjunta e pesquisadora da Universidade Federal Fluminense, vinculada ao Departamento de Comunicação Social e ao Programa de Pós-Graduação em Mídia e Cotidiano da mesma universidade. Lidera o grupo de pesquisa Mídias, redes e jovens: usos e apropriações em contextos digitais, certificado pelo CNPq. É doutora e mestre em Comunicação e Cultura pela ECO/UFRJ e formada em Jornalismo pela Universidade Federal Fluminense, com especialização em Marketing pelo Instituto Coppead/UFRJ.
} 
enquadramento da realidade e não outro. E essa necessária transparência do processo muitas vezes inexiste no jornalismo, o que faz autores como Brighenti (2010, p. 82) considerarem que a estrutura da própria mídia, ao decidir o que mostrar e o que não mostrar, é deixada fora do quadro.

Neste artigo nos voltamos a imagens da miséria, imagens de "marginalizados" sociais que não estão nas páginas policiais, que não são transformados em números, que ganham capas e têm seus corpos expostos, gerando um misto de repulsa e comoção. Quais são as reais intenções que levam esses corpos miseráveis aos holofotes? Tais imagens e tal pergunta nos surgiram em uma pesquisa mais ampla, na qual investigamos a representação no gênero grande reportagem de personagens que lidam com a vulnerabilidade em seus cotidianos. São os moradores em situação de rua, mas também pessoas linchadas, estando à margem ou não da lei, sem direito à defesa. Nas próximas páginas, os personagens são Flávio da Silva e Ely-Samuel.

Crianças nos anos 1960, o brasileiro e o porto-riquenho estão no centro de um embate midiático entre duas revistas fotográficas, a norte-americana Life $^{3}$ e O Cruzeiro $^{2}$, do conglomerado de Assis Chateaubriand. Chegamos a essas produções após nos depararmos na referida pesquisa de maiores dimensões com uma contradição: Vidas relegadas a segundo plano por sua condição social, que não seriam as escolhidas segundo critérios de noticiabilidade como o nível hierárquico da fonte ${ }^{4}$, podem estar presentes, e com destaque, em publicações de altas tiragens, caso dos dois veículos. Nos anos 1970,

\footnotetext{
${ }^{3}$ Criada em 1883 como uma revista de humor, com cartoons, charges e gravuras, a Life passa a reunir as características que a marcaram ao longo de décadas a partir de 1936, quando é comprada pela Time. Surgia ali uma revista semanal com ênfase no fotojornalismo e em fotojornalistas. Grandes nomes da área, como Robert Capa, cujas imagens de guerras fazem parte da história do século XX, integraram o time de profissionais da revista, que se pretendia popular; o objetivo era alcançar por meio dela toda a família. Life circulou interruptamente até 2000 (de 1978 ao primeiro ano do novo século se tornou mensal), voltando a aparecer em 2004 como suplemento de periódicos. Deixou de ser impressa em 2007. ${ }^{2}$ Revista semanal editada pelos Diários Associados, de Assis Chateaubriand, O Cruzeiro fez sua estreia em 10 de novembro de 1928 e circulou até 1975. Tendo a modernidade como uma de suas promessas, a revista trouxe inovações gráficas e aflorou a parceria entre fotógrafo e repórter. $\mathrm{O}$ apreço pela fotografia e o investimento em grandes reportagens se firmaram como características da publicação, que não se limitou à abrangência do território brasileiro. Através de $O$ Cruzeiro Internacional, a revista ilustrada alcançou os países vizinhos da América do Sul, além de ser lida no Caribe e nos Estados Unidos. Seu público leitor era composto principalmente de mulheres das classes média e alta.

${ }^{4}$ Os critérios de noticiabilidade definem quais pautas serão desenvolvidas em matérias e posteriormente publicadas. A existência do critério ancorado em uma hierarquia entre pessoas é apresentada por Mauro Wolf (1992). Recorrendo a duas duplas de autores, o teórico da comunicação versa tanto sobre a maior probabilidade de o acontecimento virar notícia quando ocorre em países de elite e diz respeito a pessoas de elite (GALTUNG; RUGE, 1965, apud WOLF, p. 201), quanto sobre o maior valor-notícia que o conteúdo terá ao despertar interesse do público. Em pesquisa de 1979, Golding e Elliott sugerem que o "não visualizável" consequentemente não gera o interesse referido. Esquecem, no entanto, que sempre haverá o não-visualizável, de forma que é preciso problematizar as escolhas feitas na redação.
} 
Life chegou a imprimir 8 milhões de cópias ${ }^{5}$. Já a revista de Chateaubriand teve tiragem recorde em 1954, com 720 mil exemplares quando a média de periódicos era de $100 \mathrm{mil}^{6}$. Todavia é preciso ponderar que $O$ Cruzeiro estava à época da capa aqui analisada em “[...] situação de decadência, perda de público e de vendas, e também situação financeira agravada pela falência do projeto de internacionalização; talvez (a reportagem) tenha sido a sua última grande cartada editorial” (TACCA, 2011, online).

Apresentamos neste ponto o nosso corpus: Freedom's Fearful Foe: Poverty (O temido inimigo da liberdade: a pobreza) e Flávio's rescue: Americans brings him from Rio slum to be cured (O resgate de Flávio: americanos o trazem da favela do Rio para ser curado), ambas da revista Life; Novo recorde americano: Miséria, de O Cruzeiro. Além de consulta à Hemeroteca Digital da Biblioteca Nacional, com o intuito de encontrar o material, recorremos à pesquisa de Fernando de Tacca sobre o caso do menino Flávio. Apesar do mesmo conteúdo ter sido contemplado por esse pesquisador anteriormente, acreditamos que podemos trazer novas contribuições à temática. Tacca conta a história das reportagens e dos bastidores. Nós pretendemos mesclar arcabouço teórico específico acerca do espetáculo, da midiatização e do encarceramento identitário dos indivíduos com descrição de imagens e recorte de trechos a serem discutidos. Não é nossa intenção chegar a nenhuma conclusão definitiva ou geral sobre o tema abordado, por entendermos que nosso corpus é restrito. Propomo-nos apenas a refletir sobre os referidos conceitos por meio da abordagem qualitativa dos três trabalhos jornalísticos.

Cabe ainda apresentar os personagens que motivam as reportagens. Em 1961 Life exibe o sofrimento humano a partir do olhar de Gordon Parks, enviado pela revista para registrar a miséria na América Latina. Parks conhece a família Silva na favela da Catacumba, posteriormente removida e transformada em parque na Lagoa Rodrigo de Freitas, ponto turístico da Zona Sul do Rio de Janeiro. Oito filhos a compõem, entre eles Flávio, de 12 anos, que cuida da casa enquanto os pais trabalham. Em $O$ temido inimigo da liberdade: a pobreza a revista mostra a criança alimentando seu irmão na única refeição diária; olhando para a câmera vestido em roupas maltrapilhas e sujas; padecendo em uma cama, subnutrido e asmático.

\footnotetext{
5 O dado integra dissertação de Amana Salles acerca da revista Life. Disponível em: <http://www.teses.usp.br/teses/disponiveis/27/27161/tde-03122018-152052/pt-br.php> Acesso em: 28 jul. 2019.

6 Disponível em: <https://acervo.oglobo.globo.com/rio-de-historias/com-cruzeiro-chega-asbancasmoderno-jornalismo-brasileiro-8883281> Acesso em: 28 jul. 2019.
} 
A imersão junto à família é publicada em 16 de junho, gerando rápida repercussão internacional e no próprio país. Tão rápida que em 21 de julho do mesmo ano, Flávio retorna às páginas da revista, desta vez sozinho e sorridente. A solidariedade dos norteamericanos, que fizeram doações à Life, permite trazê-lo aos Estados Unidos para um tratamento médico, mote de $O$ resgate de Flávio. Cerca de quatro meses depois da primeira reportagem, no dia 7 de outubro, O Cruzeiro publica sua revanche, Novo recorde americano: Miséria. O intuito é claro: mostrar que a miséria existe também nos Estados Unidos e que ela pode ser pior. O veículo envia o repórter fotográfico gaúcho Henri Ballot a Nova York. Sua missão é igualmente buscar fome, dor e condições subhumanas de existência. Os encontra no Spanish Harlem, bairro em Manhattan onde se concentra a comunidade latino-americana e onde convive com os Gonzalez, família porto-riquenha de dez filhos. Entre as cenas impactantes que registra, uma das crianças, Ely-Samuel, aparece deitado na cama coberto por baratas.

Até que ponto tal visibilidade é positiva para os personagens? Qual o limite para a apresentação do Outro, especialmente quando o Outro é tantas vezes vítima do esquecimento? Teriam Gordon Parks e Henri Ballot acertado nas abordagens escolhidas? Em outras palavras, questionamos se a simples exposição da pobreza, como a face oposta ao capitalismo que a sociedade nega, contribui para a transformação da realidade, e em que medida o jornalismo é capaz de desempenhar seu papel social numa sociedade hipnotizada por sua própria imagem. Conforme Brighenti (2010, p. 89, tradução nossa ${ }^{7}$ ),

Enquanto a visão otimista afirma que a visibilidade global do sofrimento inevitavelmente traz consigo o potencial de cuidar de pessoas distantes e invisíveis, a visão cética desafia a ideia de que o imediatismo visual e a "alucinação de estar lá" (Lefort, 1986) levam a qualquer preocupação real com aqueles infelizes distantes que são “como nós" (Chouliaraki 2008).

\section{Sociedade do espetáculo: vidas levadas ao palco pela mídia}

Maio de 1968. Palavras de ordem contra o conservadorismo estão nas ruas da França, assim como os trabalhadores que, entrando em greve, se somam às primeiras vozes em contestação. Elas vêm dos estudantes universitários. Os gritos que pedem a

\footnotetext{
${ }^{7}$ No original: "Whereas the optimistic view claims that the global visibility of suffering inevitably brings with it the potential of really caring for distant and otherwise invisible others, the sceptical view challenges the idea that visual immediacy and the 'hallucination of being there' (Lefort 1986) leads to any real concern for those distant unfortunates who are 'like us' (Chouliaraki 2008)".
} 
renúncia do presidente Charles de Gaulle saem a plenos pulmões de quem apenas um ano antes conhecia a mais famosa obra de Guy Debord e era envolto pelo espírito crítico que dela emanava. Os escritos presentes em A Sociedade do Espetáculo logo passam a ser discutidos e reverberados na Internacional Situacionista, movimento artístico iniciado em 1957 que ganha seu viés político a partir das contribuições profícuas do pensador francês. Por trás da ebulição nas ruas estava, portanto, um embate mais amplo acerca da "[...] relação social entre pessoas, mediada por imagens" (DEBORD, 1997 [1967], p. 14). O que Debord denuncia é a proliferação de imagens em uma sociedade do consumo, substituindo o real pelo irreal e transformando o indivíduo em mero espectador, reduzido, portanto, à passividade.

O espetáculo se apresenta como uma enorme positividade, indiscutível e inacessível. Não diz nada além de "o que aparece é bom, o que é bom aparece". A atitude que por princípio ele exige é a da aceitação passiva que, de fato, ele já obteve por seu modo de aparecer sem réplica, por seu monopólio da aparência (Ibidem, p. 16-17).

No contexto da produção imagética exacerbada que pauta as interações há a supremacia do olhar. Mas apesar desse sentido ser requerido, o indivíduo não consegue o principal através da visão: dar-se conta da dimensão espetacular do que observa. Por isso o francês insistirá na existência de um monopólio, a partir do qual "considerado de acordo com seus próprios termos, o espetáculo é a afirmação da aparência e a afirmação de toda vida humana - isto é, social - como simples aparência" (Ibidem, p. 16). Também marxista, o filósofo theco Karel Kosik reflete sobre esse cenário em Dialética do Concreto. No livro de 1976, fenômeno e essência ajudam a explicar o que ele denomina como mundo da pseudoconcreticidade, no qual o que se apresenta ao homem não é a realidade em si, apesar de assim parecê-lo. "O fenômeno indica a essência e, ao mesmo tempo, a esconde. A essência se manifesta no fenômeno, mas só de modo inadequado, parcial ou apenas sob certos ângulos e aspectos" (KOSIK, 1976, p. 15).

A vida do dia a dia é para este filósofo uma via de acesso à compreensão e à descrição do real, mas ela também falsifica a realidade, por isso mostra e esconde ao mesmo tempo. Daí advém o significado de pseudoconcreto, o falsamente concreto relacionado à aparência. Debord (1997 [1967], p. 14) igualmente utiliza o prefixo "pseudo": "A realidade considerada parcialmente apresenta-se em sua própria unidade geral como um pseudomundo à parte, objeto de mera contemplação". A passagem dialoga com a de Kosik, embora o francês encerre o indivíduo na "mera contemplação" enquanto 
o theco busca entender como é possível conhecer a realidade concreta exatamente para o homem poder transformar o que o oprime.

A partir do esclarecimento acerca da realidade fenomênica, adentramos na reportagem Novo recorde americano: Miséria, de O Cruzeiro, tratando especificamente de uma das fotos feitas por Henri Ballot, já antecipada anteriormente. O menino portoriquenho Ely-Samuel está deitado em um colchão remendado, que se encontra à mostra. Sobre o seu corpo passeiam três grandes baratas. A quarta está em cima do lençol. O corpo esquálido, a presença de insetos que se proliferam em locais com pouca higiene, o colchão aparente e roupas maltrapilhas formam um cenário que parece materializar a miséria citada no título do trabalho. A criança está entregue ao animal repulsivo, que se alimenta de detritos. Por associação, ela é o próprio detrito, que a sociedade descarta.

Essa é a mensagem indiscutível que a revista procura transmitir. Mas ela se mostrará discutível. Após a publicação da reportagem, a Time, como vimos detentora da Life desde 1936, vai atrás da família Gonzalez e afirma ter descoberto uma fraude. Os retratados teriam recebido dinheiro para posarem para Ballot (HARAZIM, 2014, online). A acusação abre margem a diversos debates acerca da ética profissional, que ultrapassam os limites deste artigo. Limitaremo-nos, por isso, a afirmar que a aparência é enganosa, podendo levar ao irreal ${ }^{8}$. Mas outras reflexões se fazem necessárias. Mesmo que a foto não fosse falsa, ainda assim o fenômeno (a cena vista) e a essência (a miséria) não seriam o mesmo. O menino subnutrido deitado em uma cama revela apenas parcialmente a vulnerabilidade social, não revela a sua causa. O problema é dotado de complexidade, envolvendo nesse caso políticas migratórias, inserção em mercado de trabalho, construção de moradias dignas, políticas públicas e até mesmo o modo de produção em vigor, pautado por desigual acesso aos bens gerados.

Há ainda a competição entre veículos por trás da foto. Time procura a família Gonzalez para contrapor críticas feitas à revista de seu grupo. O Cruzeiro deixa claro na

\footnotetext{
${ }^{8}$ Essa constatação abre um questionamento acerca do que é a verdade, tão cara ao jornalismo. Silvia Lisboa e Marcia Benetti (2015) lembram que o jornalismo se propõe a descrever e interpretar a realidade, logo precisa ser verossímil, mas a veracidade vai além desta correspondência com o real, envolve também a transparência: "É da natureza do jornalismo, como é da retórica fazer crer (BERGER, 1996; SERRA, 2016b). Nesse sentido, faz parte da prática jornalística (SOUSA, 2002) argumentar sobre por que optou por esta e não aquela interpretação dos fatos, por que selecionou este e não aquele acontecimento" (LISBOA; BENETTI, 2015, p. 15). No caso da foto de Ely-Samuel não está claro como as fotos foram feitas nem em que se baseou a decisão editorial para apresentar foto tão chocante de um menor de idade, embora saibamos os propósitos da revista $O$ Cruzeiro com a reportagem.
} 
escolha da pauta, na diagramação e em variadas passagens que pretende revidar a exposição da miséria brasileira por parte dos norte-americanos, usando igual estratégia:

Não podemos negar aqui a existência das favelas cariocas. Conhecemos o seu drama e o seu problema. Mas a miséria não é exclusividade nossa. A revista "O Cruzeiro" enviou o repórter Henri Ballot a Nova York. Como ambiente, ele escolheu um "slum" (favela) de Manhattan e, deste "slum", uma família porto-riquenha. Para os leitores que não chegaram a ver a reportagem de "Life", queremos esclarecer que seguimos, propositalmente, o mesmo roteiro e a mesma paginação daquela revista. Para melhor compreensão, reproduzimos em "fac-smile", ao lado das várias fotografias de Henri Ballot sobre os "slums", as páginas daquela publicação americana sobre as favelas cariocas (NOVO..., 1961, p. 6, grifo nosso).

O motivo do enquadramento é claro. Sabe-se porque as imagens são publicadas, já que a revista faz questão de mostrar suas reais intenções, ao atestar, por exemplo, que segue "propositalmente o mesmo roteiro e a mesma paginação" de Life, quer confrontála. A transparência, no entanto, não minimiza o fato de a competição ser mais importante que o próprio personagem, relegado a um segundo plano. A revista brasileira tenta convencer o leitor de que a pobreza nos Estados Unidos é mais nefasta, já que ocorre em uma potência econômica mundial. E assim a "angústia da fome e do desamparo", embora chamada de universal, é categorizada. Por isso O Cruzeiro lembrará a todo o momento a concentração financeira próxima a Spanish Harlem, o que é um fato, explorado pela revista, mas sem maiores contextualizações. Falta aprofundamento porque o intuito da pauta não é explorar a origem da desigualdade, mas sim que a miséria "não é exclusividade nossa", do Brasil; o objetivo é achar o "Flávio de Nova York". Nessa disputa, as imagens são ferramentas usadas por O Cruzeiro. A cama em que dormem Flávio e os irmãos fica em segundo plano quando retratada intencionalmente lado a lado do amontoado de corpos sem direção em foto do cômodo dos porto-riquenhos. O leitor é incitado a contrapor pobrezas.

Já em legenda da foto de Ely-Samuel, a miséria é utilizada para ironizar Life.

No 'apartamento' em que vive a família Gonzalez, em Nova York, as baratas passeiam, de noite, sobre o corpo subnutrido do menino ElySamuel. Na testa, um esparadrapo esconde a marca de uma mordida de rato. Seria o caso, talvez, de trazê-lo ao Brasil, para uma última tentativa de salvar esta criança condenada à morte por subnutrição. Não foi fácil conseguir esta foto (NOVO..., 1961, p. 15, grifo nosso). 
Neste trecho $O$ Cruzeiro está se referindo à segunda reportagem que Life publica sobre a família Silva. Após contar a história dos nordestinos na favela carioca, a revista arrecada cerca de US\$ 30 mil, que são usados para custear o tratamento de Flávio nos Estados Unidos. Assim, “[...] primeiro em contribuições de leitores não solicitadas e depois em um apelo discreto, a Life iniciou seu próprio esforço de resgate" (BERGER, 2018, online, tradução nossa ${ }^{9}$ ) do menino. Flávio 's rescue (O resgate de Flávio) é a capa da edição de 21 de julho de 1961. Se antes as imagens eram de dor, agora o personagem aparece sorrindo, vestindo roupas coloridas e limpas, tendo nos braços urso de pelúcia e deitado na cama do hospital infantil do Colorado, onde recebe cuidados de diversos médicos para combater a sua asma. Os norte-americanos salvam Flávio do trágico destino a que estava fadado, a morte na Catacumba. O discurso é apelativo: “É o mesmo menino - deitado então em uma cama de favela, pele junto aos delicados ossos, olhos angustiados; e agora balançando em direção aos céus, gritando 'Está bom!' com um sorriso florescendo no seu rosto" (LIFE, 1961 apud TACCA, 2011, online).

Além de abordar a intervenção médica, a edição contempla outras imagens de alegria, como a compra de roupas por Flávio, ao lado de Gordon Parks, e o intercâmbio cultural possibilitado pela estadia dele na casa de uma família portuguesa durante o tempo que passa no país estrangeiro. Flávio brinca como qualquer outra criança e os leitores de Life têm a sensação do dever cumprido. O espetáculo está completo, chegase ao final feliz, no melhor estilo ficcional, transportado para a realidade.

É possível, porém, que o espetáculo não tenha sido a intenção inicial de Parks. O jornal The New York Times lembra como ele “[...] reconheceu na época que os Estados Unidos precisavam 'limpar seu próprio quintal' em relação ao racismo e à segregação antes que pudesse abordar com credibilidade a difícil situação da América Latina”, além de admitir "[...] que os leitores em grande parte da classe média da revista não tinham que enfrentar os desafios diários de Flávio nem os de milhões de pessoas pobres perto de casa" (BERGER, 2018, online, tradução nossa ${ }^{10}$ ). Por que então aceitar a pauta? O periódico também tem a resposta: foi a esperança de causar um impacto, aquele necessário para

\footnotetext{
${ }^{9}$ No original: "Raising nearly $\$ 30,000$, first in unsolicited reader contributions and later in an understated appeal, Life began its own rescue effort".

${ }^{10}$ No original: "[...] Mr. Parks, who acknowledged at the time that the United States needed to "clean up its own yard" with regard to racism and segregation before it could credibly address the plight of Latin America. He intrinsically understood that the magazine's largely middle class readers did not have to confront Flavio's daily challenges nor those of millions of poor people close to home".
} 
gerar mudanças. "Através de suas fotografias perturbadoras, ele queria convencê-los (os leitores) de que a pobreza extrema - não importa onde - era uma injustiça e uma ameaça à humanidade, que precisava ser remediada" (Ibidem, tradução nossa ${ }^{11}$ ). Ainda é preciso citar que a infância pobre de Gordon Parks, o mais novo entre os 15 filhos de um fazendeiro do Kansas, o aproximava do drama vivido por Flávio e por outras crianças mundo afora. Parks já havia registrado a pobreza em Paris, Estoril, Porto Rico, Canadá e nos Estados Unidos (HARAZIM, 2014, online), e criou afeição especial ao menino brasileiro, com quem manteve permanente contato.

Mas não se podem negar outros fatores. O primeiro deles é a utilização de subterfúgios para a maior dramatização das cenas cotidianas, tal como o uso da teleobjetiva pelo repórter, lente que achata os planos, aproximando a favela da Catacumba do Cristo Redentor, cartão postal da cidade; ou ainda a escolha por produzir um diálogo entre a foto de Flávio e outra, que retrata seu vizinho já morto. O menino sofre enquanto um destino o espreita na página anterior. O corpo em igual posição que a sua parece sentenciá-lo a um fim trágico. Qualquer possível boa intenção não desfaz o perigo de igual sentença. É ainda preciso considerar a existência de interesses por parte da Life. E aqui podemos apontar dois deles: o interesse financeiro, por se tratar de um produto mercadológico, que objetiva a venda - o público é estimulado a comprar a revista para conhecer o "final" da história; e o interesse político, partilhado pelo governo norteamericano, como aponta Fernando de Tacca (2011, online):

Podemos claramente identificar que a reportagem de Gordon Parks estava relacionada diretamente com estratégias mais amplas de veiculação de ideias e valores cujo interesse levava a dois caminhos: sensibilização interna do público norte-americano para as políticas externas do Departamento de Estado em relação à América Latina e, assim, legitimação de ações diplomáticas e militares, e, de outro lado, alcançar também o público latino-americano, demonstrando que os EUA tinham interesse na região, se preocupavam com os problemas sociais e com o avanço dos movimentos populares com tendência de esquerda, assumindo o medo do "avanço comunista" [...] A compaixão foi o motor da ação individualizada que esse leitor médio foi levado a manifestar fazendo doações diretas para a família Silva, através da revista, e assim sentindo-se todos como parte das mudanças das condições sociais propícias para o avanço do maior inimigo norteamericano, a propagação da revolução cubana.

\footnotetext{
${ }^{11}$ No original: "Through his disturbing photographs, he wanted to convince them that extreme poverty no matter where - was an injustice and threat to humanity that needed to be remedied"
} 
Esse contexto que leva às reportagens de Life não está posto ao leitor. Mas, ao publicar a redenção de Flávio, lado a lado da exposição de sua miséria, a revista agrada a consciência dos leitores e os prova nas entrelinhas que é possível combater qualquer ameaça a partir da compaixão que muda uma realidade. Apenas uma, pois a miséria continuará a existir e pode voltar a atingir até mesmo Flávio após os 15 minutos de fama possibilitados por um regime de visibilidade que não é ingênuo. Ponderações como essas são encobertas por imagens. Afinal, a felicidade está ali, diante dos olhos de todos, sintetizada em Flávio vivendo como o menino tipicamente norte-americano, em roupa de gola alta, grandes meias, sorrindo ao ser empurrado no balanço por criança loira. Tratase do cenário ideal no capitalismo: ser a classe dominante, o que o espetáculo sabe reproduzir, como atesta Debord (1997 [1967], p. 14-15):

Considerado em sua totalidade, o espetáculo é ao mesmo tempo o resultado e o projeto do modo de produção existente [...] Sob todas as suas formas particulares - informação ou propaganda, publicidade ou consumo direto de divertimentos -, o espetáculo constitui o modelo atual da vida dominante na sociedade. É a afirmação onipresente da escolha já feita na produção, e o consumo que decorre dessa escolha.

Ely-Samuel, diferentemente, só tem a imagem da sua dor estampada. Mas ela também vende e cumpre o objetivo do acerto de contas a que $O$ Cruzeiro se propõe. A pobreza está à mercê de um jogo orquestrado pela imprensa, que a partir das imagens media as relações sociais apelando para o sensível. Como veremos adiante, Muniz Sodré fornece contribuições teóricas a essa reflexão ao atrelar o espetáculo de Debord à sociedade que também é da comunicação e da informação, entendendo, assim, a formação de uma existência baseada no capital, na mídia e na exploração dos afetos, todos eles presentes nas referidas reportagens. Antes, no entanto, cabe uma síntese a respeito das semelhanças entre os trabalhos aqui pormenorizados:

O brasileiro Flávio e o portorriquenho Ely são dois casos de focos jornalísticos de interesses distintos, mas pautados na imagem trágica ou chocante, como elementos alimentadores de sentimentos e ações ideológicas. A imagem é o lugar efetivo da significação, da sintetização simbólica e do embate mediático entre dois garotos que lutam pela sobrevivência, no qual a ideia de miséria, doença e morte é integrada como um vínculo quase indissociável e indissolúvel (TACCA, 2011, online, grifo nosso). 


\section{Bíos midiático e o encarceramento identitário: a imagem do pobre}

A imagem significa, como afirma Tacca (Ibidem). Logo, o menino brasileiro passa a significar para o Outro a partir da maneira como é representado. É por isso que Muniz Sodré defende que a mídia engendra um novo existir, "[...] um novo espaço e modo de interpelação coletiva dos indivíduos, portanto, outros parâmetros para a constituição das identidades pessoais" (SODRÉ, 2002, p. 23). Para defender sua teoria, Sodré resgata o conceito de bios dois milênios e meio ${ }^{12}$ depois de sua origem, partindo dos três gêneros de existência explicados por Aristóteles e primeiro sugeridos por Platão. Segundo a definição aristotélica, o bios theoretikos seria a vida contemplativa do filósofo, distinta da vida voltada ao fazer político, o bios politikos. O bios apolaustikos, por sua vez, representaria a existência dedicada apenas ao prazer. A tese de Sodré é que "a mediação social exacerbada, a midiatização, com espaço próprio e relativamente autônomo", implica em "uma qualificação particular da vida, um novo modo de presença do sujeito no mundo ou, pensando-se na classificação aristotélica das formas de vida, um bios específico" (Ibidem, p. 22). A mídia constitui novos parâmetros de identidade; é um espelho simulado, que não reflete meramente o mundo, o condiciona.

Não à toa, Sodré recorre a Debord em seus estudos. Afinal, a constituição de identidades aparece estritamente relacionada ao espetáculo nesta passagem do francês: “O espetáculo não pode ser compreendido como o abuso de um mundo da visão, o produto das técnicas de difusão maciça das imagens. Ele é uma Weltanschauung, que se tornou efetiva, materialmente traduzida. É uma visão de mundo que se objetivou" (DEBORD, 1997 [1967], p. 14). A palavra de origem alemã citada no trecho pode ser traduzida como visão de mundo ou cosmovisão, concepção da realidade que é anterior ao indivíduo ou, em outras palavras, uma "concepção global, de caráter intuitivo e préteórico, que um indivíduo ou comunidade formam de sua época, de seu mundo, e da vida em geral" (JAPIASSU; MARCONDES, 1996, online). No que tange às reportagens analisadas, que concepção é formada acerca miséria?

Sua causa não está aparente, mas suas consequências mostram-se em corpos marcados, expostos, desprezíveis, que causam repulsa ao mero olhar. A visão sobre eles

\footnotetext{
12 Sylvia Moretzsohn (2007, p. 98) constata essa diferença temporal ao criticar Sodré pelo que chama de "criatividade acadêmica": "[...] se "na verdade, há muito tempo se sabe que a linguagem não é apenas designativa, mas principalmente produtora de realidade' (Sodré, 2002, p. 26), então não haveria qualquer justificativa para o surgimento de um novo bios quase dois milênios e meio depois dos outros três: a virtualização seria inerente à linguagem, que é uma atividade característica do ser social - e que, portanto, o acompanha desde tempos imemoriais".
} 
está cristalizada. O que esperar de tais corpos? Que são fadados a deixarem de existir, apenas dignos de pena, que nada pode haver de inesperado em seus comportamentos a não ser o sofrimento. Tudo é previsível quanto a eles, e o que não é, como a foto do menino miserável de repente estar sorridente e cheio de vida, torna-se verossímil porque a própria ficção a concebe. As fronteiras entre o real e o irreal desaparecem.

Os corpos cuja visibilidade é tão aparente que cruzam a linha tênue entre ela e o espetáculo são fagocitados por um poder, aquele do bios midiático. E aqui se assemelham às vidas infames sobre quem escreve Michel Foucault, apesar da origem distinta que as torna conhecidas. Em A vida dos homens infames, o filósofo analisa textos dos séculos XVII e XVIII, arquivos de internamento, policiais, mensagens remetidas ao rei da França e ordens emitidas por ele. Foucault está interessado, entre outros documentos, nas lettre de cachet, as cartas assinadas pelo monarca dando seu veredicto acerca das desgraças cotidianas, como a mulher abandonada que pede a detenção do marido. Em similaridade nos pedidos recebidos pelo rei está a linguagem teatral na descrição dos acusados. A partir dela "as vidas mais dignas de pena aí são descritas com as imprecações ou com a ênfase que parecem convir às mais trágicas" (FOUCAULT, 2006 [1977], p. 211). E é neste ponto que o que Foucault (p. 210, grifos nossos) afirma sobre os infames dialoga com Flávio e Ely-Samuel:

[...] eles não mais existem senão através das poucas palavras terríveis que eram destinadas a torná-los indignos para sempre da memória dos homens. E o acaso quis que fossem essas palavras, essas palavras somente, que subsistissem. Seu retorno agora no real se faz na própria forma segundo a qual os expulsaram do mundo. Inútil buscar neles um outro rosto, ou conjecturar uma outra grandeza; eles não são mais do que aquilo através do que se quis abatê-los: nem mais nem menos.

Ambos os meninos não existem senão através daquelas imagens publicadas.

Estamos diante de um "universo carcerário", que aprisiona suas identidades, em uma alusão à pesquisa de Luis Antonio Baptista. No artigo Walter Benjamin e os anjos de Copacabana, ele parte de ensaio clássico do intelectual alemão para analisar o documentário Edifício Master, de Eduardo Coutinho. Baptista se depara no filme de 2002 com narrativas de personagens comuns a respeito de suas próprias vidas. Implodidos do que deles o público espera ver e ouvir, esses personagens surgem na frente das câmeras sem poderem ser enquadrados na simplificação do senso comum. Assim, Alessandra Alves de Souza tachada unicamente como a prostituta por ter sua renda ligada ao sexo, tem desejos de infância, como lanchar no fast food. Esse é o efeito de não deixar-se 
aprisionar, de que falou primeiro Benjamin (1987 [1985], p. 189), embora em outro contexto, tratando o cinema como o propulsor para a explosão, já que a grande tela permite aos espectadores empreenderem "viagens aventurosas".

Podemos considerar que essa explosão também seja possível no jornalismo. Para tanto, e especialmente no caso das pautas que abarcam a vulnerabilidade social, deve haver o cuidado em evitar aprisionamentos e espetáculos. Quem aborda o perigo da exposição de tais personagens é Andrea Mubi Brighenti (2010) ao estudar a visibilidade na teoria social. Entre os riscos citados por ele, que vão desde gostar, sadicamente, do espetáculo da dor alheia à anestesia moral e conivência com o que é apresentado, está a ameaça da generalização e do preconceito, que reforçam a marginalidade. No entender do filósofo, existem dois extremos ambos sujeitos a consequências negativas às vidas retratadas: "Para as minorias, assim como a invisibilidade pode facilmente levar à falta de reconhecimento, a supervisibilidade pode facilmente levar à deturpação, distorção, desautorização e inferiorização" (BRIGHENTI, 2010, p. 87, tradução nossa $^{13}$ ).

\section{Considerações finais}

Há trabalhos em que o jornalismo parece decretar e encerrar o miserável a um futuro já pronto, renegando a ele qualquer outra condição que não seja a sub-humana, o ser humano em degradação. A partir do teor dramático, a visão cristalizada do Outro é entregue pronta para o leitor, seja ela imagética ou escrita. É o que acreditamos que acontece em $O$ temido inimigo da liberdade: a pobreza e Novo recorde americano: Miséria. Os olhos são atraídos pela força do espetáculo com a dor do Outro, mediante a abordagem escolhida para tratar do tema. Mesmo quando $O$ resgate de Flávio apresenta imagens de alegria, tem-se a naturalização: estão ancoradas em superficialidade.

Neste artigo investigamos os regimes de visibilidade a partir dos quais duas vidas marginalizadas vêm à tona em reportagens da grande imprensa e nos perguntamos até que ponto eles poderiam ser positivos para os sujeitos retratados. Tal questionamento não nega a importância de trabalhos veiculados na mídia acerca da pobreza. A comunicação pode não só respeitar o Outro como impactar positivamente realidades, e de forma ampla. $\mathrm{O}$ potencial, porém, pode ser perdido quando disputas ideológicas e mercadológicas entram

\footnotetext{
${ }^{13}$ No original: "The issue of the visibility of ethnic, sexual and moral minorities and marginal people reveals how social representations lean towards and are always dangerously close to stereotyping. For minorities, just as invisibility can easily lead to lack of recognition, supervisibility can easily lead to misrepresentation, distortion, disempowerment and inferiorisation".
} 
em cena, quando o bios midiático encerra o sujeito em imagens estereotipadas, colocando em risco a existência já ameaçada por condições sociais adversas.

Ely-Samuel e Flávio tornam-se fantoches para objetivos distantes de uma análise aprofundada de seus cotidianos, mostrando que o tempo de contato do repórter com suas fontes não é suficiente para que ele possa constituir discursos de alteridade. Pois em ambos os casos, apesar da imersão jornalística, o imediatismo visual fala mais alto, fazendo com que a balança entre a concepção otimista e a pessimista da visibilidade pese mais para o ceticismo a que se refere Brighenti (2010). Uma consideração que podemos deixar a respeito do que até agora foi apresentado é, pois, a necessidade primeira de um pressuposto ético que, aliado à transparência e à fuga do imediatismo, tão caro ao espetáculo, consiga preservar a vida exposta à audiência.

\section{Bibliografia}

BAPTISTA, Luis Antonio. Walter Benjamin e os anjos de Copacabana. Disponível em: <https://app.uff.br/slab/uploads/texto93.pdf> Acesso em: 6 maio 2019.

BENJAMIN, Walter. A obra de arte na era da reprodutibilidade técnica. In: Obras escolhidas: magia e técnica, arte e política. $3^{a}$ edição. São Paulo: Brasiliense, 1987, v. 1, p. 165-196.

BERGER, Maurice. Gordon Parks on Poverty, the 'Most Savage of Human Afflictions' The New York Times, Nova York, 10 set. 2018. Disponível em: <https://www.nytimes.com/2018/09/10/lens/gordon-parks-on-poverty-the-mostsavageof-human-afflictions.html> Acesso em: 2 jul. 2019.

BRIGHENTI, Andrea Mubi. Visibility in social theory and social research. Reino Unido: Palgrave Macmillan, 2010.

DEBORD, Guy. A sociedade do espetáculo. Rio de Janeiro: Contraponto, 1997.

FOUCAULT, Michel. A vida dos homens infames. In: Estratégia, podersaber. Ditos e Escritos vol. IV. $2^{\text {a }}$ edição. Rio de Janeiro: Forense Universitária, 2006, p. 203222.

HARAZIM, Dorrit. Gordon Parks na Catacumba - Parte II. Zum, Revista de Fotografia, São Paulo, 20 out. 2019. Disponível em: <https://revistazum.com.br/colunistas/gordon-parks-2/> Acesso em: 2 jul. 2019.

JAPIASSU, Hilton; MARCONDES, Danilo. Weltanschauung. In: Dicionário Básico de Filosofia. $3^{\text {a }}$ ed. Rio de Janeiro: Zahar, 1996.

Disponível em: 
<https://sites.google.com/view/sbgdicionariodefilosofia/weltanschauung > Acesso em: 2 ago. 2019.

KOSIK, Karel. Dialética do concreto. $2^{\text {a }}$ edição. Rio de Janeiro: Paz e Terra, 1976.

LISBOA, Silvia; BENETTI, Marcia. O jornalismo como crença verdadeira justificada. Brazilian Journalism Research, São Paulo, v. II, n. 2, p. 10-29, 2015.

MORETZSOHN, Sylvia. Pensando contra os fatos: jornalismo e cotidiano: do senso comum ao senso crítico. Rio de Janeiro: Revan, 2007.

NOVO recorde americano: Miséria. O Cruzeiro, Rio de Janeiro: Editora O Cruzeiro, ano XXXIII, nº 52, p. 6-17, out. 1961. Disponível em:

$<$ http://memoria.bn.br/DocReader/docreader.aspx $? \mathrm{bib}=003581 \&$ pasta=ano\%20196\&pe sq=Henri\%20Ballot> Acesso em: 3 jul. 2019.

SODRÉ, Muniz. Antropológica do espelho: uma teoria da comunicação linear e em rede. Petrópolis, RJ: Vozes, 2002.

TACCA, Fernando de. O caso Flávio. Projetos especiais Studium, Revista da UNICAMP, São Paulo, fev. 2011.

Disponível em: <https://www.studium.iar.unicamp.br/caso_flavio/index.html> Acesso em: 29 jul. 2019.

WOLF, Mauro. Teorias da Comunicação. $9^{a}$ edição. Barcarena, Portugal: Editoria Presença, 2006.

Texto recebido em: 30/10/2019

Texto aprovado em: 06/02/2020 